multipliers measuring $I$ in. diameter by $1 \frac{1}{2}$ in. long have been made and with improved materials multipliers of even smaller size with greater temperature stability, sensitivity and resonant frequency can be made. The applieations of multipliers up to the present time have been limited, but the trend in electronics is towards extremely complex pattern recognition systems which utilizo autocorrelation and cross-correlation of wave shapes, opera- tions which require the use of an analogue multiplier. The computational power of a multiplier compares well with that of a fast digital computer, for with a bandwidth of $5 \mathrm{kc} / \mathrm{s}$ and an accuracy of 1 por cent it can offect. ively multiply two 7 -bit numbers 10,000 times per sec: and a network containing 100 multipliers could oasily do more arithmetic per see than the fastest digital com. puter yot built.

\title{
THE IMPERIAL COLLEGE OF SCIENCE AND TECHNOLOGY
}

$\mathrm{T}$ HE fifty-fifth annual report of the Governing Body of the Imperial College of Science and Technology* covers the year ended July 31,1962 , in which the number of full-time students increased by 53 to 2,735 , with $a$ decrease of 4 in postgraduate students, and the academic staff increased by 25 to 444 full-time members. Tho report refers to the difficulty in recruiting and retaining staff of the right calibre, mainly because of the disparity between academic salaries and the inducements offered by industry. This may seriously affect the implementation of the integrated academic plan; but great concern is also expressed as to the effect of the restricted grants to be made available in the next quinquennium, as announced in June 1962. From October 1963 the undergraduate tuition fee has been increased to $\mathrm{£85}$, inclusive of College and University examination and registration fees, the postgraduate foe remaining at $£ 75$ exclusive of those charges. Discussions are proceeding with the Architectural Association on the possible incorporation of the Architectural Association School within the College. The Governing Body considers that a close connexion between leading schools of engineering, particularly civil and structural engineering, and of architecture could be of great value. The $£ 17.5$ million 'ceiling' imposed on the overall cost of the Jubilee Expansion Scheme has necessi-

* Imperial College of Science and Technology (University of London). (London: Imperial College of Science and Technology, University of London, 1962.) tated postponing the start of two of the major buildings. with adverse effects on the Departments of Mathematies, Meteorology and Chemistry concerned.

The Rector's report notes that, during the year, students obtained. 200 higher and 498 first degrees, science degrees accounting for 46 per cent of the total, and the 400 students awarded the D.I.C. included 296 technologists. Of the 653 overseas students, 406 were from the Commonwealth and four-fifths were postgraduates. Of the United Kingdom students, 27 per cent came from within 30 miles of the College. The academic staff now includes 50 professors and 73 readers, and developments in fields lying on the borderline between important disciplines include the introduction of a course on the application of engineering to medicine and biology and the institution of a chair in the history of science and technology. Library facilities were greatly improved during the year and, referring to research, Sir Patrick Linstead notes that of 37 research projects at present listed by the National Research Development Corporation. 6 originated at the College. Grants for research and income from research contracts totalled $\$ 523,000$, the Department of Scientific and Industrial Research supporting 77 projects with an annual value of $£ 235,000$. Some notes on recent research are included in the Rector's report, and a list of publications during the year, arranged by departments, is appended, together with a list of special lectures.

\section{ENVIRONMENTAL PHYSIOLOGY AND PSYCHOLOGY IN ARID CONDITIONS}

\begin{abstract}
A SYMPOSIUM on "Environmental Physiology and A Psychology in Arid Conditions" was held recently at the Central Drug Research Institute in Lucknow, under the auspices of Unesco and the Government of India. The arrangements were made by Dr. M. Batisse of the Department of Natural Sciences of Unesco, and locally by Dr. B. Mukerji, director of the Institute and chairman of the symposium, with Dr. J. Swarbrick of the Unesco South Asia Science Co-operation Office at Delhi. Thirteen countries were represented by approximately fifty delegates.

The scientific papers and discussion were divided into nine sections, as follows: the neurophysiology of heat exposure, psychological aspects, human performance and comfort standards, comparative hoat physiology, the significance of solar radiation in heat balance, water and electrolyte problems, nutrition and heat, medical climatology, and physiological anthropology. The proceedings, which will be publishod by Unesco, drew strength principally from two sources: first, from a number of pre-circulated reviews of the topics chosen for discussion, and secondly, from recent fundamental and field research, particularly in Israel and the French Sahara.

Unesco will publish these reviews separately and within the next few months. They range in subject-matter from
\end{abstract}

physiological adjustments to heat, to the somewhat vexed definition of tropical neurasthenia. The authors include F. A. Fuhrman (United States, effects of heat on the action of drugs), E. M. Glaser (Great Britain, circulatory adjustments to heat), A. Henschel (United States, field test methods), R. A. Kenney (Great Britain, renal adjustments), G. E. Lambert (France, thermal comfort), D. H. K. Lee (United States, arid zone physiology). W. V. Macfarlane (Australia, endocrine adjustments), J. Mayer (United States, arid zone nutrition), E. Sehreider (France, physiological anthropology), and F. Sargent (United States, tropical neurasthenia). Available also to the symposium participants was a review of the works of Soviet scientists on arid zone problems (prepared by the U.S.S.R. Academy of Medical Sciences and translated from the Russian). These documents are listed hore because they were the background to many of the short papers read at the symposium, but there were also unrelated communications of value, notably by C. von Euler (Sweden) on the body thermostat and its setting, and by K. Schmidt-Nielsen (United States) on comparative physiology in arid climates.

The papers relating to recent studies in Israel and the French Sahara, along with similar contributions from Indian and Australian scientists, provided most of the 
participants with fresh and stimulating information. The Institute of 'Technology at Haifa, the Negev Institute in Boorsheba, the climatic unit at the Tel Hashomer hospital in Tel Aviv, and the French centre for study and information on human problems in arid zones (PROHUZA), have all contributed significantly to our knowledge of heat physiology; and Unesco has done well to fostor, throughout its major project on scientific research on arid lands, studies which are carried out in the field rather than in climatic chamber's in temperate countries. Doveloping communities in arid regions, given a now way of life and now standards of hygiene, must sooner or later face the issues of how the local climate affects health and industrial programmes; and the studies which have been made so far, principally on expatriate European and Amorican ('ommunities, are not altogether relevant. In this respect the work of W. V. Macfarlane (Australia) on long-term heat adaptations in domestic stock animals is particularly valuable, and it is encouraging to learn that similar comparative research is carried out in Egypt and at the Central Indian Arid Zone Research Institute in Jodhpur. and that the PROHUZA team has examined the indus. trial-omployment aptitude and long-term adaptations of nomadic tribes in the Sahara.

The visiting participants at the Ineknow symposium are indebted to Unesco and the Govermment of India, and to Dr. B. Mukerji for his hospitality at the Central Drug Research Institute. The published Proceedings will contain much valuable information anel should stimulate continued interest in the subjoct in the Middle East and in South-East Asia.

C. S. LETTHEA1)

\section{CARDIOVASCULAR ANATOMY AND PATHOLOGY}

\section{A}

SYMPOSIUM on 'Cardiovascular Anatomy and Prof. K. R. Hill, was held in the meeting room of the Zoological Society of London during November 28-29, 1962. This symposium, which was attended by more than 100 research workers from a wide variety of medical and veterinary departments, reflected the growing interest in the functional anatomy and pathology of the cardiovascular system.

During the first morning session, under the chairmanship of Prof. E. W. Walls, Prof. F. Navarrina Gamez (Santiago de Compostela, Spain) described researches conducted in collaboration with Prof. R. G. Harrison on the effect of cortisone on the vascularization of bone in normal and ovariectomized female rats. These researches, like others during the symposium, demonstrated the need for a detailed analysis of the functional anatomy of organs and tissues when investigating their vascularization. During the first four weeks after ovariectomy there is a reduction in the extent of vascularization of the metaphyses and vertebral bodies. This is not as extensive as in cortisonetreated rats, however, and is followed, within ten weeks, by an increased vascularization. The primary metaphyseal ischæmia can be correlated with a disorganization of cell columns in the epiphyseal cartilages of long bones, which persisted in cortisone-treated rats. These alterations in vascular pattern are accompanied by changes in the pattern and density of trabeculæ in metaphyses and vertebræ; in some animals there is an obvious fragmentation of trabeculæ in vertebral spines.

Dr. Helen N. Duke (London) summarized her investigations on the hæmodynamics of the pulmonary circulation. Factors concerned with the pressure and flow and change of blood volume in the circulation were discussed. The pressure flow is concave to the flow axis. The curve is affected by changes of left atrial pressure and by vasomotor reactions of the pulmonary blood vessels. Increase of pulmonary arterial inflow rate or left atrial pressure increases the volume of blood in the pulmonary blood vessels; some of the increased blood volume is the result of capillary dilatation. It is probable that those vessels responsible for pulmonary vascular resistance are not those responsible for changes in lung blood volume.

The functional anatomy of the vertebral venous system was described by Dr. J. D. W. Tomlinson (London). The variability of the posterior vena cava, particularly among aquatic mammals, was clearly and beautifully demonstrated. The value of the azygos venous system as a collateral circulation for drainage of structures below the level of the diaphragm was also discussed.

Dr. R. L. Holmes (Birmingham) reviewed present-day knowledge on the anatomy of the hypothalamo-hypophyseal vascular system, with particular relation to the hedgehog and ferret, and showed that there is no isolation of the vascular supply of one part of the gland from that of another or from the hypothalamus. The portal vessels are responsible for carrying the greater part of the normal blood supply to the pars distalis, and play a major part in the mediation of hypothalamic control over the pituitary.

In the afternoon session on November 28, under the chairmanship of Prof. Harrison, Mr. D. Sykes (Liverpool) reviewed some of his work on the blood supply of the human kidney. There is a segmental pattern of branching of the renal artery within the substance of the kidney which is, however, subject to some variation. A continuous arcuate artery does not exist. The venous pattern does not correspond with the arterial supply, and evidence was presented to suggest that blood vessels which penetrate the kidney capsule are carrying blood which is passing centripetally into the substance of the kidney. The longitudinal sulcus, when it exists, does not correspond with Brodel's line, which is neither linear nor avascular.

Mr. D. B. Moffat (Cardiff) summarized the research work which he had been conducting with Dr. Julia Fourman on the fine vascularization of the mammalian kidney; he: demonstrated the difference to be found in various mammalian species, and clarified the nature of the vasa recta, which he found to be mostly composed of capillaries.

Prof. D. F. M. Bunce II (Des Moines, Iowa) read a paper on the architecture of the distended arterial wall, and stressed the differences in histological appearance of arteries in the collapsed and distended state, and between arteries from various sites in the body. In the teaching of students he had found the use of casts of the renal vascular tree of great value for their appreciation of the true nature of glomerular structure.

Dr. J. L. Braithwaite (Liverpool) described experiments he had been conducting with Dr. C. J. Fairhurst on collateral venous drainage of the spleen. Pursuing his original investigations on the regional distribution of the splenic vessels and their branches to the rat spleen, he had shown that the venous drainage of a region of the spleen the hilar vein of which had been occluded was effected through a plexus of newly formed veins encircling the site of ligature. Following interruption of the main splenic vein, collateral channels, consisting of preformed anastomoses (evident at $24 \mathrm{~h}$ ) newly formed vessels (visible at 7 days) and portal-systemic anastomoses (which developed 3 weeks later), became established.

Dr. J. E. Wright (Liverpool) concluded the afternoon session by deseribing the effects of interruption of the vascular pedicles of the liver in the experimental animal, and compared the effects of ligation of the hepatic artery with those of interruption of the portal vein. Arterial 